\title{
FOUR-PHASE METHOD IN ESP LISTENING: APPLYING TOPIC-BASED DIALOGUE-INTERVIEWS FOR INTERNATIONAL RELATIONS
}

Anastasia Tananykhina, Ludmila Neudachina, Nadezhda Timchenko, Anastasia Dudkina

St Petersburg University, Russia

\begin{abstract}
The paper presents the result of a research into the issue of four-phase method of ESP listening using a topic-based dialogue-interview which contributes to the development of communicative competence of IR students of Saint Petersburg State University. Different aspects of the issue are studied through an attempt to identify students' difficulties in ESP listening and the role of sociocultural component in four-phase ESP listening method. The effectiveness of four-phase method of ESP listening is evaluated by means of a survey conducted among students of International Relations Faculty of Saint Petersburg State University. The survey demonstrates that four-phase method of ESP listening contributes to eliminate lexical and sociocultural unawareness and develop communicative competence.
\end{abstract}

Key words: ESP listening, professional vocabulary, topic-based dialogue interview, background information, communicative language teaching, integrated skills phase

\section{INTRODUCTION}

University programmes in International Relations of Saint Petersburg State University aim to educate highly qualified professionals, who will be equipped with ample specialist knowledge enabling them to conduct international negotiations, achieve a profound understanding of international politics, and defend the interests of their country on the global political arena; this knowledge must be combined with superior communication skills and an excellent command of several foreign languages. Degree courses in International Relations involve theoretical and practical training in an impressive variety of areas, such as keeping official correspondence, conducting analytical work, hosting international delegations, establishing and maintaining contacts with foreign countries, and participating in the activities of international organizations. Upon completion of their university course, International Relations graduates are expected to have mastered verbal interaction, negotiation and persuasion skills and to be able to handle interpersonal and public communication freely, comfortably and with ease. ESP skills form a crucial part of degree training in International Relations and may be included in the teaching content early into the university course (Rubtsova and Dobrova 2020).

Submitted January $16^{\text {th }}, 2021$, accepted for publication March $13^{\text {th }}, 2021$

Corresponding author: Anastasia Tananykhina. St Petersburg University, 11 Lieutenant Shmidt Emb.,

St Petersburg 199034, Russia| E-mail: asya-tn@yandex.ru 
ESP listening is acknowledged as one of the most complex skills to acquire for foreign language learners. Listening per se represents a multi-dimensional cognitive process involving numerous mental operations (analysis, synthesis, induction, deduction, to name just a few). Listening, in turn, is closely linked with speaking as in natural conversations participants take it in turns to talk and listen (Rogova and Vereschagina 1998). International Relations undergraduates and graduates have to practice various types of communicative listening in the course of their careers and during studying; one example is fielding questions during press conferences and briefings.

Students of English for International Relations are exposed to audio content in a variety of genres, ranging from news reports and lectures to documentaries and interviews with politicians. Each of these genres has its own distinctive features and poses unique challenges to ESP learners. Our research will focus on political interviews, a genre most commonly used for ESP listening, which provides an example of professional communication in real-life settings.

The reason for this research was the situation that came to light when the ESP teachers faced the problem of third-year students' unpreparedness for ESP listening and discussion of relevant political issues. The lack of knowledge of cultural, political and social realities and the lack of professional vocabulary create certain difficulties at ESP listening and speaking that can result in a more large-scale obstacle in developing communicative competence.

The goal of this research is to present a method for applying topic-based dialogueinterviews in ESP listening classrooms with the aim to develop listening and speaking skills as well as eliminate students' lexical and sociocultural unawareness. To reach the stated goals we elaborated four-phase method of ESP listening using as theoretical foundations the works of I.L Kolsenikova, O.A. Dolgina, B. Paltridge and S. Starfield.

\section{THEORETICAL BACKGROUND}

Communicative language teaching is one of the most effective EFL methodologies today. The core principle of this approach lies in the similarity of the learning process with the real process of communication (Levchenko 2007). In other words, the communicative approach requires that language learning should be organized in such a way as to simulate real-life communication. Some activities most commonly associated with this approach are discussions, dialogues, debates, "snowball" exercises, student projects and interviews.

\subsection{Sociocultural component}

The sociocultural component features prominently in all areas of professional activity where English is used as a communication medium. For example, the sociocultural realities of a lawyer whose education was shaped by a Muslim culture and Shari'a law will differ from those of an expert in modern European law which is grounded in the Roman legal tradition; the two lawyers may also have differing perspectives on human rights and individual freedom. For an international relations professional, the knowledge of history, culture and traditions of other countries is absolutely vital as intercultural communication and can only be successful if built on mutual respect and understanding.

Sociocultural competence can therefore be construed as the sum of knowledge about the target country, its history, facts of its political and economic life, and key political figures. One of the most effective tools for the development of sociocultural competence 
for students of English for International Relations is independent student research, undertaken prior to performing actual listening comprehension assignments with the aim to collect the relevant background sociocultural information and place the listening assignment into context. For instance, students preparing to watch the interview with Omar Abdullah (Chief Minister of Jammu and Kashmir) on BBC's HARDtalk may be requested to do some preliminary research on Omar Abdullah's biography and his country, with a focus on the following questions:

1) What is Omar Abdullah background and education?

2) Why is Jammu and Kashmir an unusual Indian state?

The development of communicative competence relies on several drivers which are crucial to intercultural communication. These include student research and collection of sociocultural data about the target country; exposure to authentic audiovisual content about the problems faced by the target country; students' proactive approach during the class; group discussions and opinion exchange as well as students' argumentative monologues based on the audiovisual content. When combined, all of these drivers contribute to balanced improvement of students' communicative competence in its linguistic, discursive and sociocultural dimensions.

\subsection{Teaching ESP listening}

Listening is a receptive language skill which involves perception, understanding and active processing of information contained in oral speech (Galskova and Gez 2015). ESL listening and ESP listening, doubtless, share many common features and cognitive mechanisms and require certain basic skills and knowledge. However, ESP listening also necessitates a plethora of specialist knowledge and skills to achieve comprehension of audiovisual content in narrower subject fields. The principal challenges for ESP listening students are accents, intonation, speech pace and specialist vocabulary.

To successfully cope with listening comprehension tasks, learners must possess three types of knowledge:

1. Linguistic knowledge (knowledge of phonology, vocabulary, grammar and syntax).

2. Discursive and pragmatic knowledge.

3. Factual knowledge (background or extralinguistic information) (Paltridge and Starfield 2013).

Adequate listening comprehension depends on the learner's ability to perceive, identify and recognize English speech sounds as well as "convert" them into words and phrases. Knowledge of syntax and sentence structure is necessary for dividing oral utterances into meaningful parts. Finally, vocabulary knowledge facilitates students' perception, segmentation and interpretation of spoken utterances.

ESP listening is based on two macro-skills: listening comprehension and listening/ speaking. Listening comprehension involves the ability to understand specific information as well as the key message and gist of the text, to work out the meaning of the utterance on the basis of linguistic and cultural knowledge, to apply prediction, to understand specific parts of the text while ignoring inessential details (Paltridge and Starfield 2013). Another important aspect of ESP listening for International Relations students is the need to comprehend a broad variety of accents since English, being a language of international communication and diplomacy, is frequently used by non-native speakers.

Interactive listening forms part of every oral verbal interaction, where the participants generally take turns to talk and listen (Kolesnikova and Dolgina 2001). For this reason, 
the skills associated with interactive listening partly overlap with speaking skills, such as the ability to choose appropriate turn-taking strategies, obtain and hold the floor or ask clarification questions.

Most modern methods of L2 instruction rely on a three-stage model for teaching listening comprehension. A brief overview of these stages is presented below:

1. Pre-listening. The purpose of this stage is to remove possible lexical and/or grammar obstacles to understanding the audio content; relevant background information is also presented and discussed. Typically, learners at the pre-listening stage will also be offered tasks to train their skills of prediction, e.g. Predict/Try to guess what the speakers will discuss.

2. Active listening. This stage trains goal-oriented comprehension of spoken text (listening for gist, listening for detail, listening for specific information) and often involves activities like multiple choice exercises, gap filling, true-false statements or comprehension questions.

3. Post-listening. The stage following the active listening is used to develop a range of skills. This may involve practicing specialist vocabulary which occurred in the recording; learners may also be offered speaking and communication activities, engage in discussions based on the interview or exchange opinions about the conduct of the dialogue participants.

To teach International Relations students ESP listening we have introduced a fourth stage, which we have termed the integrated skills phase. The key goals at this stage are to review and apply the specialist vocabulary introduced during the previous three stages and to develop communicative skills by means of a dialogue-interview. The importance and effectiveness of incorporating role play into the learning process has been emphasized by many researchers, notably I.P.Gladilina, F.Leizinger, T.G.Liubimova, D.G.Mead and M.F.Stronin.

E.G.Azimov and A.N.Shchukin identified the following types of interviews:

- prepared interviews, based on a pre-set list of questions (the journalist usually records the interviewee's answers);

- interviews focusing on a single subject, problem or situation;

- extended interviews addressing a broad range of issues, held with the aim to obtain detailed in-depth information on a specific problem (Azimov and Schukin 2009).

A somewhat different classification of interviews was provided by E.A.Kostromina:

- informative interviews (focus on new facts; the interest in the interviewee is of lesser importance);

- expert interviews (solicit the opinion of an authority figure);

- problem interviews (focus on identifying and comparing different opinions on a specific problem);

- personal interviews (focus on the interviewee's personality) (Kostromina 2014).

All these types of interviews can be effectively used in ESP contexts. A well-selected mixture of interview types introduces variety to classroom work as well as helps to enrich students' vocabularies and rhetorical skills.

Although the authors cited above differ in their approaches to interview typology, both classifications refer to a form of interview that revolves around a particular issue or subject ("problem interview", in E.A.Kostromina's terminology). This group of interviews, herein referred to as topic-based dialogue-interviews, will be addressed in our research in more depth.

Topic-based dialogue-interviews is one of the most productive and effective tools for improving foreign language skills. There are few, if any, other genres of dialogue where interest in human individuality and the need for open interaction are manifested with more intensity than during a verbal exchange in authentic interview settings. 
For purposes of this research, topic-based dialogue-interview will be defined as an exercise aimed at developing expressive speaking skills; it is a type of role play in realistic situations, where one of the students plays the part of a journalist approaching an interviewee (played by another student) for information. The "journalist" must organize the dialogue, plan and formulate the questions using the active vocabulary, and be able to support or challenge the "interviewee's" opinions. In other words, the "journalist's" task is to initiate and maintain a dialogue on the given subject, while ensuring effective psychosocial rapport with the "interviewee" and fostering an open and friendly atmosphere throughout the conversation.

Being a situation- and context-specific activity, topic-based dialogue-interviews provide vast opportunities for practicing the active language of the lesson in realistic contexts, "with all emotional intensity, spontaneity and goal-orientedness of natural face-to-face communication" (Yudin 1978).

Teaching foreign languages is geared towards forming communicative competence - a multifaceted concept which comprises, among others, linguistic, discursive and sociocultural dimensions (Kolesnikova and Dolgina 2001). In turn, the sociocultural dimension of communicative competence also incorporates diverse elements, including sociolinguistic, ethnocultural and cross-cultural ones (Solovova 2010).

Thus the issue of using topic-based dialogue-interview at ESP listening and speaking requireы a method based on the research that, firstly, defines a pool of problems that teachers and students face in the ESP classroom and, secondly, designs methodology of dealing with them.

\section{PROBLEMS OF ESP LISTENING}

A range of difficulties and problems arise at ESP listening, but the most crucial ones are lexical difficulties and sociocultural unawareness. Lexical difficulties pose a particular problem for ESP students as each professional field involves a vast body of specialized vocabulary and terminology, which needs to be explored, learned and trained. Other features that may impede understanding for ESP listeners are idioms and allusions, which abound in political interviews; one good example is the phrase Queen of Hearts used by Russian Foreign Minister Sergei Lavrov during his BBC interview in reference to a character from Lewis Carroll's "Alice in Wonderland".

Sociocultural unawareness may create a substantial obstacle in ESP listening. Sociocultural competence includes knowledge about the target country, its history, facts of its political and economic life, social situation and key political figures. The lack of such knowledge can impede understanding for ESP listeners or lead to mistakes and misunderstanding. For example, while listening to the interview of Ali Amrullah Saleh without knowing basic facts about Taliban movement it can be hard to understand why the speaker, on the one hand, stresses the importance of peace talks with its representatives but, on the other, is rather cautious and does not sound very enthusiastic about such talks.

\section{METHODS AND ACTIVITIES}

In the next sections of our paper, we will analyse the application of four-phase method of using topic-based dialogue-interviews in ESP listening settings among $3^{\text {rd }}$ year students of Faculty of International Relations of Saint Petersburg State University and within the 
framework of this method we will design ways to eliminate lexical and sociocultural unawareness. The observations below are based on our experience of using a bank of interviews on the topic "Global Conflicts and Terrorism" in classes of English for International Relations; the BBC interview with Ali Amrullah Saleh is used as a case study. The key stages of the ESP listening activity organized around this content will be reviewed.

\subsection{Pre-listening phase}

To prepare students for listening to any interview, the teacher needs to address some obstacles which may hamper learners' understanding of the audio/video content. The first important step is to outline the key subjects covered in the interview and encourage the learners to research essential background information on these subjects. This extralinguistic information will sensitize the learners to the interview context and to the political realities which determine the overall tone of the conversation. The knowledge of background information also helps to understand the interviewee's reactions and the goals pursued by the journalist. Additionally, targeted information-gathering closes some knowledge gaps which can seriously impede comprehension of a political interview (e.g. references to political/ historical events; names of political, military or terrorist movements and their leaders).

One effective way of organizing learners' data research is to offer them a set of focus questions, for example:

Find information about the following:

1. The history of the Taliban movement.

2. The goals of the Taliban and its recent activities.

3. An overview of the international involvement in Afghan affairs.

4. The current political situation in Afghanistan.

5. Common problems the country faces.

To lift vocabulary barriers, a mix of out-of-class and classroom activities is used. In preparation for the subsequent listening activity, students are given a home assignment to compile a short glossary with the essential vocabulary relating to the background questions. The teacher prepares their own glossary using the interview vocabulary which may present difficulties for the learners. To further reduce the comprehension burden, students are offered a series of pre-listening vocabulary activities in class, such as matching exercises based on the teacher's glossary; see Fig. 1:

\begin{tabular}{|ll|l||}
\hline \multicolumn{3}{|l|}{ Match the ports to build combinations from the video } \\
\hline 1. & To eracicate & a) cultivation \\
\hline 1. & Polixed & a) fighting terrorism \\
\hline 1. & Global frontline & a) intimidation \\
\hline 1. & War exiausted & a) economy \\
\hline 1. & To have people & a) pove-ty \\
\hline 1. & Opium & a) counry \\
\hline 1. & Viable & a) in the field \\
\hline 1. & Conspiracy & a) bag \\
\hline 1. & Resort to & a) theory \\
\hline
\end{tabular}

Fig.1 Pre-listening vocabulary activity 


\subsection{Active listening phase}

Given that media interviews may be fairly long, several strategies can be used to fit the listening content to the available classroom time, for example:

1. Watch part of the interview (first 7-10 minutes)

2. Break down the interview into several segments, each followed by a different type of activity.

In this research, we chose to divide the interview with into parts of a convenient length which addressed different topics. The first part of the interview with Ali Amrullah Saleh covers Afghanistan's domestic problems; the second part reviews the international relations of the country. Some examples of the activities which may be offered at the active listening stage are presented below (see Fig. 2):

\footnotetext{
1a. Watch the presentation to the program and answer the following questions:

1 . What event does the host mention?

2. How many Afghan soldiers died in the last five years?
}

1b. Watch the first part (up to $12.32 \mathrm{~min}$ ) and answer the following questions

1. Does Mr. Saleh think that Afghanistan can keep fighting Taliban after the withdrawal of westen forces? Why?

2. How much territory does the government control? Does Mr. Amrullah Saleh agree with the statistics mentioned by the host?

3. What are the achievements of the government in the last 5 years?

4. What problems are still unsolved or aggravated?

5. What reasons does Mr. Saleh give for the government's failure to solve most problems?

1c. Watch the second part mark whether the statements are TRUE or FALSE

1. Afghanistan's relations with West are rather negative

2. ISIS is present in Afghanistan

3. Mr Saleh considers Pakistan one of the key allies

4. Mr Saleh isn't sure that Trump's administration will continue to support Afghanistan

Fig. 2. Active listening activities

\subsection{Post-listening phase}

The active listening stage may be followed by exercises providing students with opportunities to train the new vocabulary; see Fig.3:

Fill in the gaps with some words and phrases below.

Eradicate poverty, war-exhausted country, mixed bag, global frontline fighting terrorism

1. Now when western forces are withdrawing, it is really time for this to give peace a chance.

2. The government's achievements are a On the one hand, they managed to provide some kind of stability, but on the other, the poverty rate is increasing and the death toll is highest for the last 2 years.

3. The West should perceive Afghanistan not as a charity case, but as a partner, as

The U.S. military first began targeting Taliban narcotics facilities with airstrikes and Special Operations raids in November 2017 when jumped to record highs in Afghanistan

Fig. 3. Fill in the gaps exercise 
The activities are aimed at training the following key vocabulary on the topic "Global Conflicts and Terrorism" (see Fig. 4): Poverty, to eradicate poverty, Political/economic meltdown, Global frontline, Fighting terrorism,
War exhausted country, Viable economy/country, Resort to intimidation, Conspiracy, To
withdraw forces, To aggravate a situation, To flee homes, Opium cultivation etc

Fig. 4. Glossary

At the post-listening stage, the teacher formulates questions for discussion, e.g. "What is your impression of the interviewee? Do you find his/her arguments convincing?". The discussion may take place in pairs, small groups or as a class activity, depending on the students' level of English. Apart from developing oral communication skills, this exercise helps to contextualize and practice the active vocabulary on the topic "Global Conflicts and Terrorism" - a topic of particular interest for students of International Relations.

\subsection{Intergrated skills phase}

At the final stage of the activity, the learners break into pairs to roleplay the interview they were exposed to at the active listening stage. One of the students in each pair adopts the role of the journalist; the other takes the part of the Afghani Vice-President. The students are not required to reproduce the interview verbatim; they may reformulate the questions and even change the answers if they found the interviewee's original responses unconvincing. The activity is divided into four stages.

1. Preparation and instructions. The teacher formulates the subject for the interview, prepares the handouts and provides clear instructions to the students, setting out the goals, objectives, time frame and expected outcome of the assignment. In our case, the subject of the interview is the current situation in Afghanistan; the goal of the task is to roleplay the conversation between the journalist and the Afghani Vice-President.

2. Task performance. If necessary, the active vocabulary and grammar may be revised under the teacher's guidance prior to dialogue work. The students are then divided into pairs, with each pair receiving a set of role cards to be studied (one for the "journalist", one for the "interviewee"), and the interview is roleplayed (time allocated for dialogue work: 8-10 minutes).

Sample card: Student A

You are a TV presenter. Ask the Vice-President about:

- Current political, social and economic situation in Afghanistan, recent attacks.

- Relations with the West and Pakistan.

Remember to

- introduce your guest;

- initiate the conversation;

- develop your own ideas and counterarguments;

- be polite.

\section{Sample card: Student B}

You are Vice-President of Afghanistan. Answer the TV presenter's questions.

Remember to

- provide good arguments;

- emphasize your government's achievements;

- create a positive image. 
3. Presentation. The students perform their interviews in front of the class.

4. Analysis and conclusions. The teacher and students engage in a joint discussion, summarizing the results of the interview, analyzing errors and providing recommendations for subsequent interviews.

\section{DISCUSSION}

To evaluate the effectiveness of the four-phase method in ESP listening we held a survey among third-year students of International Relations Faculty of Saint Petersburg State University who used this method at their ESP classes. At the initial stage of the survey, students were requested to report the difficulties they faced while watching or listening to topic-based political interviews. The findings supported and reinforced our theoretical considerations. The principal difficulties for the students were associated with unknown vocabulary and new realia (30\% and $29 \%$ of the answers, respectively). Few of the students experienced grammar difficulties during listening comprehension activities. Speech pace and accent did present some challenges, although the accent caused less problems than could reasonably have been expected; see Fig. 5.

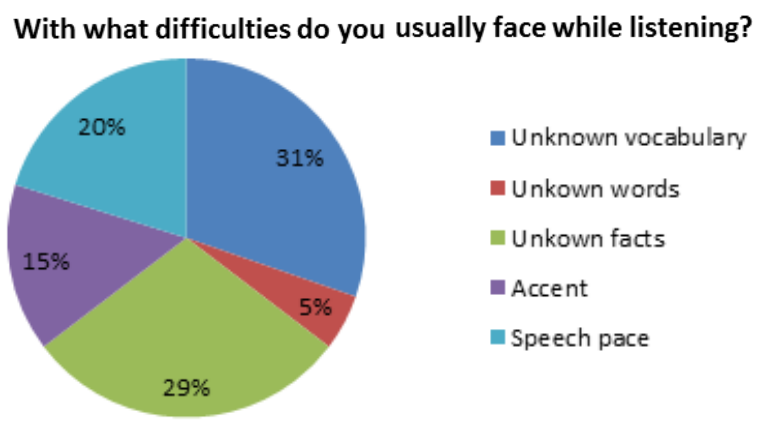

Fig 5 Difficulties while listening

The second stage of the survey was conducted upon completion of the activities based on Ali Amrullah Saleh's interview. The aim of this stage was to establish the work forms which most effectively relieved learner difficulties during the integrated skills phase, where students roleplayed their interviews. The survey findings suggest that during the active listening stage the students seemed to benefit most from the vocabulary exercises and the teacher's glossary combined with prior background data research $(38 \%$ and $40 \%$ respondents, respectively). In the integrated skills phase, however, the factors which contributed to better comprehension were background information (40\%), student glossaries $(31 \%)$, and vocabulary exercises $(30 \%)$. It may be concluded that background information was equally effective in alleviating learner difficulties both at the listening and discussion stages, whereas student glossaries proved less useful compared to vocabulary exercises and teacher glossaries. During the pair work, however, the situation was reversed, with student glossaries exceeding the teacher's glossary in effectiveness; see Fig. 6 and 7. 


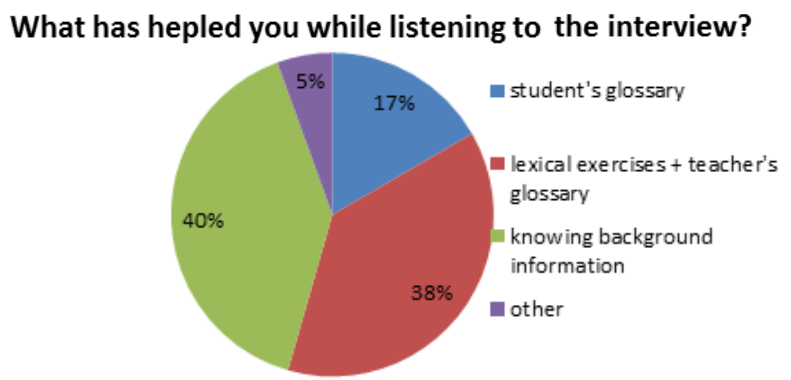

Fig. 6 What has helped while listening

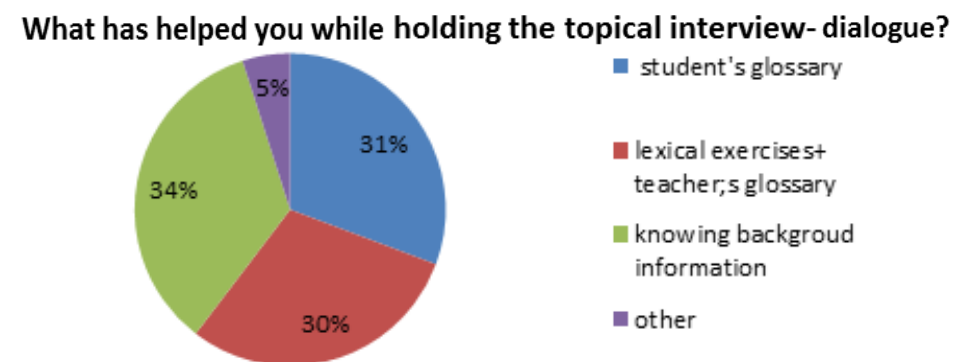

Fig. 7. What has helped while speaking

\section{CONSLUSION}

The research has shown that the four-phase method is more effective in the ESP teaching context as it enables to expose students to specialist vocabulary at the early stages of the listening activity; the vocabulary can then be practiced by means of various exercises aimed at improving students' communication skills (e.g. gap-filling, multiple choice, paraphrasing exercises). The pre-listening stage in ESP settings is usually longer and more diverse compared to ESL situations as it combines vocabulary extension activities with the development of students' sociocultural competence through targeted research. The active listening stage is inevitably more limited in terms of time and content; this stage is aimed at checking students' understanding of the audio content through a range of activities (multiple choice, matching, answering questions, gap filling, etc). The post-listening stage in ESP classrooms is, again, more extensive compared to ESL environments and involves focused vocabulary practice and gradual transition to speaking activities, where students will exchange opinions about the audio content (in case of topic-based interviews, the discussion will centre on the arguments and the conduct of the interview participants).

Finally, the integrated skills phase represents a synthesis of various language skills and focuses on language production; this is the stage when students can practice using the active vocabulary on the subject of the interview (here, "Global Conflicts and Terrorism") and develop their verbal reasoning, persuasion and interaction skills while expanding their sociocultural competence. This stage forms one of the key components of ESP listening activities and makes it possible to simulate situations of professional communication in highly realistic settings. 
To deal with the problem of lexical and sociocultural unawareness there are two main methods. Dealing with lexical difficulties includes specially designed and pre-selected lexical exercises and compiling their own glossaries on the given topic by students while the search for background information eliminates sociocultural unawareness.

\section{REFERENCES}

Azimov E.G., Schukin A.N. A New Dictionary of Methodogical Terms and Notions (Theory and Practice). Moscow: IKAR, 2009

Galskova N.D., Gez N.I. Theory of Foreign Languages Teaching: Linguodidactics and Methodology. Moscow: Akademia, 2015

Kolesnikova I.L., Dolgina O.A. English-Russian terminological reference book on methods of teaching foreign languages. - SPb.: Russian-Baltic Information Center BLITZ: Cambridge University Press, 2001

Kostromina E.A. Rhetoric. Moscow, Berlin: Direct-Media, 2014

Levchenko V.V. An Integrated Approach to Professional and Pedagogical Training of Students. Moscow: Moscow psychological and social institute, 2007

Paltridge B. and Starfield S. The Handbook of English for Specific Purposes. WileyBlackwel, 12013

Rogova G.V., Vereschagina I.N. The methodology of teaching English. Moscow: Prosveschenie, 1998

Rubtsova S., Dobrova T., ESP/LSP/GE Fusion as Implementation of Education Continuity. Ideas from the Perspective of Fostering Vital Skills of Generation Z in the Shadow of New Reality: Case Study. The Journal of Teaching English for Specific and Academic Purposes vol. 8, no 3, 2020 <https://doi.org/10.22190/JTESAP2003319R > (2 February 2021)

Solovova E.N. Methodology of Teaching Foreign Languages. Moscow: ACT, 2010 